\title{
Seasonal Development of Ontogenic Resistance to Downy Mildew in Grape Berries and Rachises
}

\author{
Megan M. Kennelly, David M. Gadoury, Wayne F. Wilcox, Peter A. Magarey, and Robert C. Seem
}

First, second, third, and fifth authors: Department of Plant Pathology, Cornell University, New York State Agricultural Experiment Station, Geneva 14456; and fourth author: South Australian Research and Development Institute, Loxton, South Australia 5333.

Current address of M. M. Kennelly: Department of Plant Pathology, Kansas State University, Throckmorton Hall, Manhattan 66506. Accepted for publication 26 August 2005.

\begin{abstract}
Kennelly, M. M., Gadoury, D. M., Wilcox, W. F., Magarey, P. A., and Seem, R. C. 2005. Seasonal development of ontogenic resistance to downy mildew in grape berries and rachises. Phytopathology 95:14451452 .

Clusters of Vitis vinifera and V. labrusca are reported to become resistant to Plasmopara viticola at stages of development ranging from 1 to 6 weeks postbloom. It has been suggested that resistance is associated with loss of the infection court as stomata are converted to lenticels, but the time of onset, cultivar variation, and seasonal variation in ontogenic resistance has remained uncertain, as has the comparative susceptibility of stem tissue within the fruit cluster. In New York, we inoculated clusters of V. vinifera cvs. Chardonnay and Riesling and V. labrusca cvs. Concord and Niagara at stages from prebloom until 5 to 6 weeks postbloom. Berries were infected and supported profuse sporulation until 2 weeks postbloom, and pedicel tissue remained susceptible until 4 weeks postbloom. Although berries on later-inoculated clusters failed to support

coloration, shriveling, reduced size, or loss of berries. When the epidermis of discolored berries that initially failed to support sporulation was cut, the pathogen emerged and sporulated through incisions, indicating that lack of sporulation on older symptomatic berries was due to infection at an early stage of berry development followed by conversion of functional stomata to lenticels during latency. We repeated the study on Chardonnay and Riesling vines in South Australia and found that the period of berry and rachis susceptibility was greatly increased. The protracted susceptibility of the host was related to the increased duration and phenological heterogeneity of bloom and berry development in the warmer climate of South Australia. The time of onset and subsequent expression of ontogenic resistance to $P$. viticola may thus be modified by climate and should be weighed in transposing results from one climatic area to another. Our results can be used to refine forecast models for grapevine downy mildew to account for changes in berry and rachis susceptibility, and to focus fungicide application schedules upon the most critical periods for protection of fruit.
\end{abstract} sporulation, discoloration and necrosis of berry tissues was often noted, and necrosis of the pedicel within such clusters often led to further dis-

Downy mildew of grapevine (Vitis spp.), caused by the oomycete Plasmopara viticola, is one of the most widespread and destructive diseases of grapevine, particularly in viticultural areas with relatively high annual rainfall (6). Most cultivars of $V$. vinifera, which encompasses most wine and table grapes, and many cultivars of V. labrusca, which are processed for juice and jelly, are susceptible to downy mildew. Cultural controls provide only limited suppression when the environment is favorable for disease development. Consequently, downy mildew is managed principally by fungicides $(15,16)$. To date, much emphasis in research has been placed upon elucidating the complex interactions between $P$. viticola and the vineyard microclimate required for infection $(3,4,17,18,26)$. In contrast, temporal changes in the susceptibility of the host have received little attention. A better understanding of factors such as seasonal changes in host susceptibility could improve disease management and redirect fungicide applications toward the period when the host is at greatest risk. Such understanding could then be integrated into forecasting models such as DMCast, a model previously described by our research group (21).

Grapevine tissues have been reported to develop ontogenic, or age-related, resistance to several other fungal pathogens as they

Corresponding author: D. M. Gadoury; E-mail address: dmg4@ cornell.edu

* The $\boldsymbol{e}$-Xtra logo stands for "electronic extra" and indicates that the online version contains supplemental material not included in the print edition. Figure 1 is in color online.

DOI: 10.1094/PHYTO-95-1445

(C) 2005 The American Phytopathological Society
Additional keywords: adult plant resistance, disease management. age. For example, young grape berries are highly susceptible to Uncinula necator and Guignardia bidwellii, but they become resistant as they age, and this information has improved management of the diseases caused by these pathogens $(7,10,13,14)$. The time of onset of ontogenic resistance to these diseases in fruit clusters varies among cultivars of $V$. vinifera, such as Chardonnay and Riesling, and V. labrusca, such as Concord $(9,10,14)$. Ontogenic resistance to downy mildew is also reported to occur $(6,15$, $16,19)$ but the time of onset of resistance among $V$. vinifera and $V$. labrusca cultivars and the specific changes in susceptibility among berry and stem tissues have not been described precisely.

Plasmopara viticola infects only through stomata, which become nonfunctional on grape berries as they convert to lenticels $(1,2)$. It has been suggested $(12,15,19)$ but not demonstrated experimentally, that grapevine clusters become resistant to downy mildew after this conversion because the pathogen thereafter lacks an infection court. However, the density of stomata and the timing of their conversion to lenticels on berry versus stem tissue are variable. Several studies $(1,2,20,22)$ indicate that the number of stomata per berry varies with cultivar. Gregory (12) reported that stomata develop into lenticels by the time berries are "pea-sized" but claimed that $P$. viticola is able to infect older berries by growing through the pedicels into the berries. However, studies of stomatal development can only suggest a range of times during which changes in susceptibility might occur. They do not address directly when, in what organs, and to what extent it occurs. For example, based on stomatal development in different cultivars and tissues, the susceptibility of fruit clusters could be interpreted to last anywhere from 1 to 6 weeks after bloom $(1,2,6,12,15,19,20)$. 
Furthermore, the organ-specific nature of susceptibility to downy mildew in some cultivars makes it difficult to extrapolate resistance in leaves to fruit and vice versa. For example, the interspecific hybrid cv. Chancellor has highly susceptible fruit, but foliage is nearly immune. Conversely, the interspecific hybrid cv. Delaware has highly susceptible foliage, but fruit are rarely infected, despite the presence of functional stomata (20). We cannot assume a priori that $V$. vinifera and $V$. labrusca, or even cultivars within a species, will have the same patterns of seasonal susceptibility.

Our objective was to determine the temporal distribution of susceptibility to downy mildew in grape clusters within two $V$. vinifera cultivars and two V. labrusca cultivars in two distinct climatic zones.

\section{MATERIALS AND METHODS}

Vineyard sites. Studies were performed on $V$. vinifera cvs. Chardonnay and Riesling and V. labrusca cv. Concord vines at a mixed planting at the New York State Agricultural Experiment Station (NYSAES) in Geneva, NY; on V. labrusca cv. Niagara vines in a commercial vineyard near Geneva, NY; and on cvs. Chardonnay and Riesling vines in research vineyards at the South Australian Research and Development Institute (SARDI), Loxton, South Australia. The Chardonnay/Riesling/Concord vineyard in Geneva was planted in 1974 with $2.4 \mathrm{~m}$ between vines and $2.7 \mathrm{~m}$ between rows, and vines were Umbrella-Kniffen trained and cane-pruned. The Niagara vineyard was planted with $2.9 \mathrm{~m}$ between rows, $2.3 \mathrm{~m}$ between vines and was cordon-trained and mechanically hedge-pruned. In Loxton, the Chardonnay vineyard was planted in 1975, with two rows $3.4 \mathrm{~m}$ apart and $2 \mathrm{~m}$ spacing between vines, and the Riesling vineyard was planted in 1968 with $3.4 \mathrm{~m}$ between rows and $1.6 \mathrm{~m}$ between vines. Both Loxton vineyards were spur-pruned.

We needed to produce clusters that were free of disease and, at the scheduled inoculation times, free of fungicide residues. The Chardonnay/Riesling/Concord vineyard in Geneva was treated with a variety of fungicides (azoxystrobin, kresoxim-methyl, captan, or mancozeb) applied with a hooded-boom sprayer every 10 to 14 days to prevent background diseases. During fungicide applications, clusters that had been inoculated previously or were scheduled to be inoculated within 2 weeks were shielded during fungicide applications by covering the clusters with plastic bags as described previously $(9,10,14)$. The Niagara vineyard in Geneva was treated with fungicides approximately every 2 weeks but our row of experimental vines was left untreated. To protect fruit clusters from pesticide drift, we placed small plastic bags over the clusters during spray applications as noted above. The Loxton vineyards were not treated with fungicides during 2001 and 2002, and due to the dry climate there were no natural infection periods of downy mildew.

Grape flowers have fused petals that form a calyptrum, and petal fall is commonly called "capfall." Bloom dates (defined as average $50 \%$ capfall) in Geneva 2001 were 14 (Concord), 15 (Niagara), and 19 June (Chardonnay and Riesling). In Geneva in 2002, bloom dates were 20 June (Concord and Niagara) and 23 June (Chardonnay and Riesling). In Geneva in 2003, bloom occurred 24 (Concord and Niagara) and 26 June (Chardonnay and Riesling). Grapevine bloom is more heterogeneous in warmer climates (11), and therefore we were able to find clusters in both the prebloom and bloom stages on the same date in Loxton. Because of this heterogeneity, some of our prebloom inoculations were performed on the same date as bloom inoculations. In Loxton, 50\% capfall occurred on 6 November (Chardonnay) and 14 November (Riesling) in 2001, and 31 October (Chardonnay) and 1 November (Riesling) in 2002.

Inoculation procedures. On each occasion, the inoculum was composed of an uncharacterized mixture of isolates from previously inoculated grapevine seedlings and/or mature field vines.
The infected source material was incubated at $100 \%$ relative humidity (RH) overnight at 20 to $25^{\circ} \mathrm{C}$ to induce sporulation. A mist of distilled water was used to wash fresh sporangia from the lower surface of the sporulating leaves. The resulting sporangial suspension was collected in a beaker and adjusted to a concentration of $8 \times 10^{4}$ to $1 \times 10^{5}$ sporangia per $\mathrm{ml}$. We then applied the sporangial suspension to the target tissue to run-off using a hand-sprayer and enclosed the inoculated tissue overnight in moistened plastic bags sealed with a twist tie. Field inoculations were performed at dusk or on cloudy afternoons to ensure the bags did not overheat in direct sunlight. The wet bags were removed within $3 \mathrm{~h}$ after sunrise the next morning.

Sporangial suspensions were used within $1 \mathrm{~h}$ of preparation. We checked the quality of inoculum by separately inoculating leaves in the vineyard and then assessing lesion development 7 to 10 days later. In 2002 and 2003, we also checked inoculum quality by placing a drop of the sporangial suspension onto a glass slide and microscopically observing 100 sporangia for germination 2 to $12 \mathrm{~h}$ after the suspension had first been prepared. In all cases, the vineyard leaves became infected, and at least $70 \%$ of sporangia released zoospores (data not shown).

Experimental design and analysis. Grape clusters were inoculated at different stages of development to allow construction of a distribution of susceptibility. Developmental stages of fruiting clusters at time of inoculation were considered treatments, which were randomly assigned to vines at each site. At each stage of development, we inoculated three to six clusters on each of three to five vines. Vines were considered experimental units with clusters as subsamples. Uninoculated control vines were included in the design as a check for natural background levels of downy mildew, and these were bagged during fungicide treatments as described previously.

For all sites, years, and cultivars, we inoculated clusters at 7 to 16 days prebloom and at bloom. We also inoculated at the following additional times. In 2001 in Geneva, we inoculated Chardonnay, Riesling, Concord, and Niagara clusters at 7, 14, 21, and 28 days after bloom (DAB). In 2002 in Geneva, we inoculated Chardonnay, Riesling, Concord, and Niagara at 6 to 8, 12 to 14, 19 to 22,25 to 30 , and 32 to 35 DAB. In 2003 in Geneva, we added an inoculation of Chardonnay and Riesling at 11 DAB. In Loxton in 2001, we inoculated Chardonnay and Riesling vines at 7, 14, 21, and 28 DAB. In Loxton in 2002, we inoculated Chardonnay vines at $6,8,11,13,18,20,26,33$, and $41 \mathrm{DAB}$ and Riesling vines at 7, 10, 13, 16, 20, 27, 34, and $41 \mathrm{DAB}$. On the day of inoculation, we measured the equatorial diameters of 10 berries on each of five clusters as an additional indicator of berry development.

In the Geneva experiments, symptom and sign development was recorded weekly (2001 and 2002) or bi-weekly (2003) by misting clusters with distilled water on the evening before the assessment and covering them with a plastic bag overnight to promote conditions favorable for sporulation. The following morning, the bags were removed and symptoms and signs were assessed visually. In 2001, we estimated the percentage of berry and pedicel area that supported sporulation (Fig. 1A and B). In 2002 and 2003, we additionally recorded the percentage of berries with discolored/necrotic tissue but which did not support sporulation (Fig. 1C) and the presence or absence of sporulation on the rachis (Fig. 1A). In 2003, we additionally assessed the percentage of pedicels within a cluster that was necrotic (Fig. 1D).

In the Niagara vineyard on 16 July 2003, we observed pathogen sporulating on 3 to $7 \%$ of the berry and pedicel surfaces on the uninoculated control vines. Thus, for treatments assessed near that time, we present the disease values that were observed minus the severity seen on the controls. After 16 July, the natural disease level increased to $44.4 \%$ (discoloration on berries) and $36.3 \%$ (sporulation on pedicels), and we were unable to distinguish disease caused by our inoculations from disease caused by natural 
infections. Thus, the treatments assessed after 16 July are not included in the analysis.

In the Loxton vineyards, we assessed disease development 2 weeks after inoculation, whereupon clusters were harvested and incubated at $100 \% \mathrm{RH}$ at room temperature $\left(20\right.$ to $\left.25^{\circ} \mathrm{C}\right)$ overnight. We then recorded the percentage of berries supporting sporulation or with discoloration and the incidence of sporulation on pedicels and the main rachis. Ten randomly selected, uninocu-

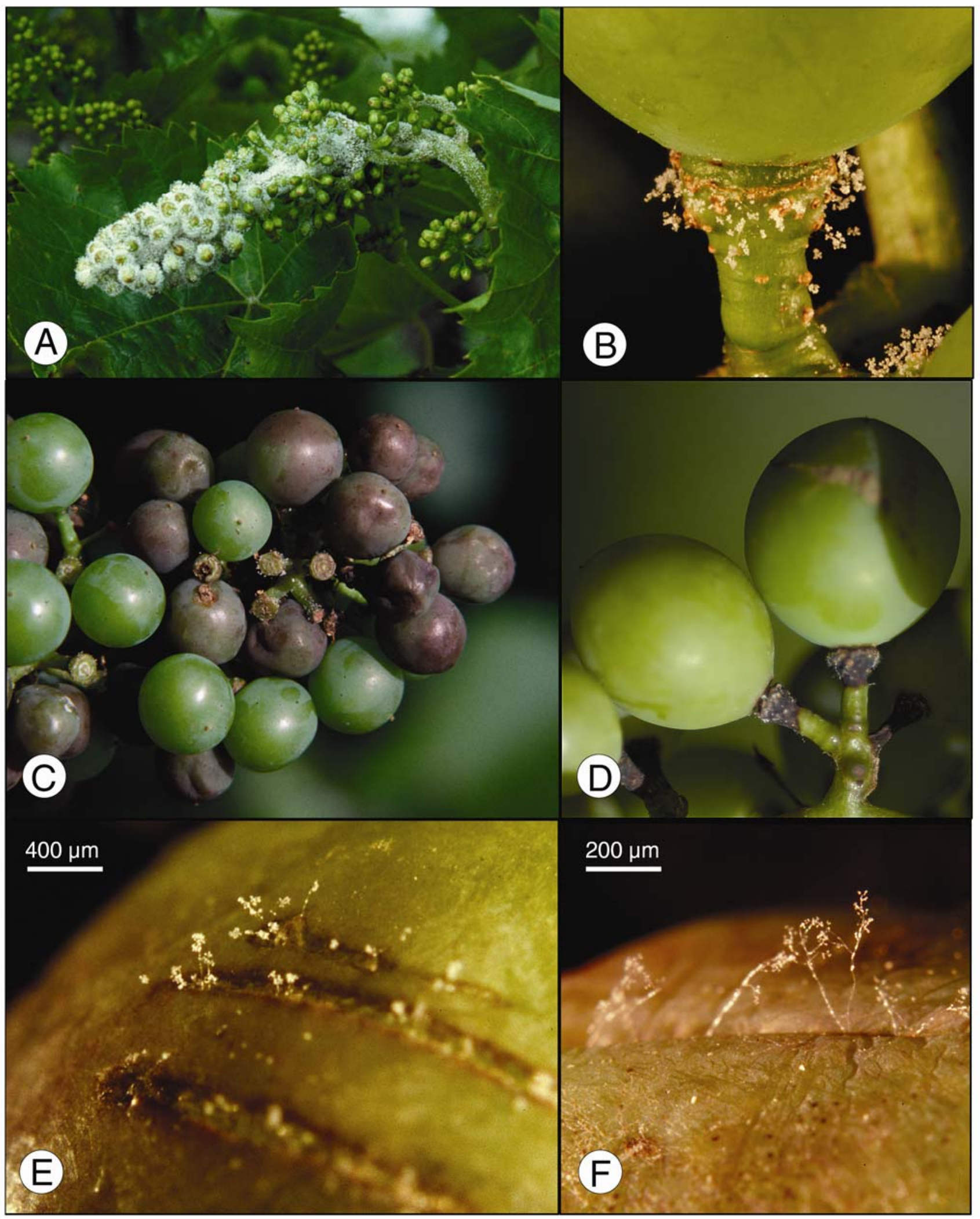

Fig. 1. Symptoms and signs of grapevine downy mildew. A, Sporulation on prebloom flowers, pedicels, and rachis. B, Sporulation on pedicel of berry prior to appearance of berry symptoms. C, Discoloration on berries with necrosis of pedicel and/or sporulation upon pedicels. D, Necrotic pedicels of berries prior to appearance of berry symptoms. $\mathbf{E}$ and $\mathbf{F}$, Emergence of sporangiophores through incisions in the epidermis of symptomatic postveraison berries. Conversion of stomata to lenticels following infection prevented emergence of sporangia prior to creating the incisions. 
lated clusters were similarly harvested, incubated, and examined to check for natural background infection.

To determine if discolored berries that failed to support sporulation had indeed been infected and colonized by $P$. viticola, but had failed to support sporulation due to conversion of functional stomata to lenticels, we collected approximately 20 symptomatic (discolored) berries at veraison in 2001, and made shallow incisions in the epidermis with a razor blade. The berries were incubated overnight at $25^{\circ} \mathrm{C}, 100 \% \mathrm{RH}$, and were examined microscopically for sporangiophores emerging through the incisions or elsewhere on the berries (Fig. 1E and F). The experiment was repeated in 2005 with the following modification. Three samples of 100 discolored berries collected at veraison were divided among two treatments. Shallow incisions were made in the epidermis of berries within one group, while those in the control group were left intact. All berries were incubated overnight as described above, and were then examined microscopically. The incidence of sporangiophore emergence through incisions or elsewhere was recorded.

Statistical analysis and modeling. To compare among sites, years, and cultivars, we set the maximum severity of disease observed for each site/year/cultivar combination to 1.00 and scaled the severity of disease observed at each phenological stage within each distribution to the maximum. To further simplify the analysis, we based comparisons on the severity of berry infection, because the total amount of diseased pedicels consistently approximated the total amount of diseased berries, i.e., if a pedicel supported sporulation or was necrotic, its berry also supported sporulation or was necrotic. We then converted the independent variable from $\mathrm{DAB}$ to cumulative degree-days (base $10^{\circ} \mathrm{C}$ ) postbloom to
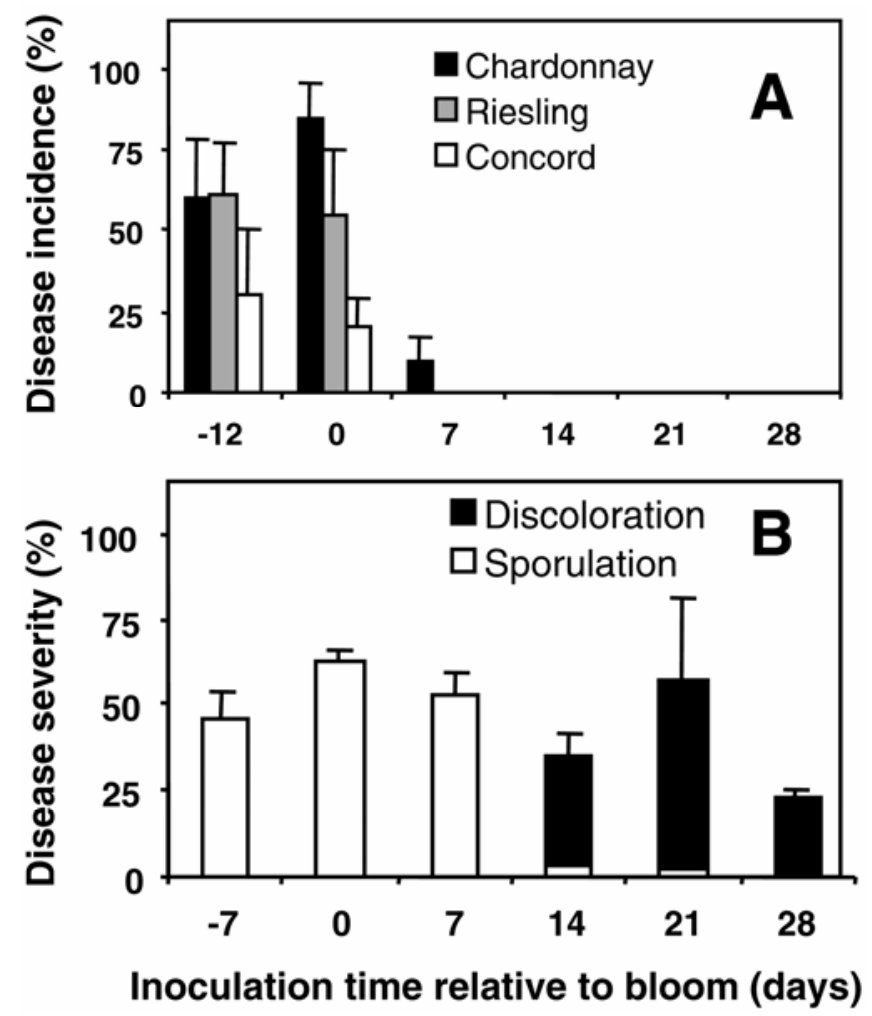

Fig. 2. Downy mildew (Plasmopara viticola) incidence and severity in 2001 in Geneva, NY. A, Disease incidence on clusters of Vitis labrusca 'Concord' and $V$. vinifera 'Chardonnay' and 'Riesling'. B, Disease severity on clusters of V. labrusca 'Niagara'. Clusters were inoculated at the indicated times relative to the date of bloom, and disease incidence (percentage of clusters with symptomatic berries) or severity (percentage of cluster surface that either supported sporulation or was discolored) was assessed 2 weeks after inoculation. Error bars represent one standard error of the mean (Concord, $n=$ 4; Chardonnay and Riesling, $n=5$; and Niagara, $n=3$ ). adjust for seasonal differences in postbloom temperature and hence rates of fruit development.

We pooled the Geneva data within 75 cumulative degree-day increments separately for each cultivar. This degree-day interval approximated the heat-unit accumulation observed between the discrete phenological stages of the fruit cluster. Regression analysis was then used to yield separate models for Chardonnay, Riesling, Concord, and Niagara that described the relative susceptibility of fruit clusters based upon degree-day accumulation after bloom. We then tested for differences among regression coefficients for the models of each cultivar. The Loxton data were similarly analyzed but were not pooled with the Geneva data, as the time of flowering in Loxton, and hence the development of ontogenic resistance, was more temporally heterogeneous.

\section{RESULTS}

In general, clusters of all cultivars at all sites were most susceptible at or before bloom and at these stages sporulation was the most conspicuous sign. In most cases, if a berry supported sporulation or was discolored, the pedicel also supported sporulation or was discolored. At later stages of berry development, susceptibility and symptom or sign development varied by cultivar, site, and year. For example, disease incidence in the Geneva Chardonnay/ Riesling/Concord vineyard in 2001 was highest at prebloom and bloom, and fell to nil or trace levels thereafter (Fig. 2A). The maximum observed severity of downy mildew in the Chardonnay/ Riesling/Concord vineyard was often below 5\% in 2001 (data not shown). In the Geneva Niagara vineyard in 2001, berries supported profuse sporulation when inoculated at 12 days prebloom, at bloom, or 7 days postbloom (Fig. 2B). Sporulation on berries was negligible following inoculations at subsequent stages, but the pedicels still supported sporulation when inoculated through 28 days postbloom, and the berries on those pedicels became discolored (Fig. 2B).

In Geneva in 2002, Chardonnay, Riesling, Concord, and Niagara berries were most susceptible and supported abundant sporulation when inoculated 14 to 16 days prebloom. Little to no disease developed on Riesling clusters inoculated at bloom or later stages (Fig. 3C), nor on Chardonnay and Concord berries inoculated at 7 and $6 \mathrm{DAB}$, respectively, or later (Fig. 3A and E). Twenty percent of berries in Niagara clusters inoculated at 7 DAB (mean berry size approximately $7.4 \mathrm{~mm}$ ) developed symptoms, but only trace levels of disease developed at 14 DAB and later (Fig. 3G).

In Geneva in 2003, clusters of all cultivars were again most susceptible at prebloom and bloom (Fig. 3B, D, F, and H), and severity typically declined thereafter. Severity of disease on Chardonnay clusters ranged from 20 to $60 \%$ through 13 DAB (mean berry size approximately $4.8 \mathrm{~mm}$ ), but only trace disease levels developed at 20 DAB (mean berry size approximately $7.1 \mathrm{~mm}$ ) and beyond (Fig. 3B). Riesling clusters developed only trace levels of disease when inoculated at all postbloom stages (Fig. 3D). Concord clusters exhibited a similar pattern, with moderate to high severity until $13 \mathrm{DAB}$ (mean berry size approximately $12.4 \mathrm{~mm}$ ) (Fig. 3F). Niagara clusters were no longer susceptible at $14 \mathrm{DAB}$ (mean berry size approximately $7.8 \mathrm{~mm}$ ) (Fig. 3H).

In 2001, we observed $P$. viticola sporulating from incisions cut into discolored berries that had previously failed to support sporulation, indicating that the pathogen had colonized internal tissues and survived there, but was no longer able to emerge through stomata to sporulate (Fig. 1E and F). In 2005, sporangiophores emerged through natural openings in the unwounded epidermis (i.e., stomata partially converted to lenticels) on only $2.7 \%$ (standard error $=2.9 \%$ ) of the postveraison symptomatic berries. When the epidermis was wounded, sporangiophores were observed to emerge from shallow incisions in the epidermis in $71.3 \%$ (standard error $=6.9 \%$ ) of the berries . 


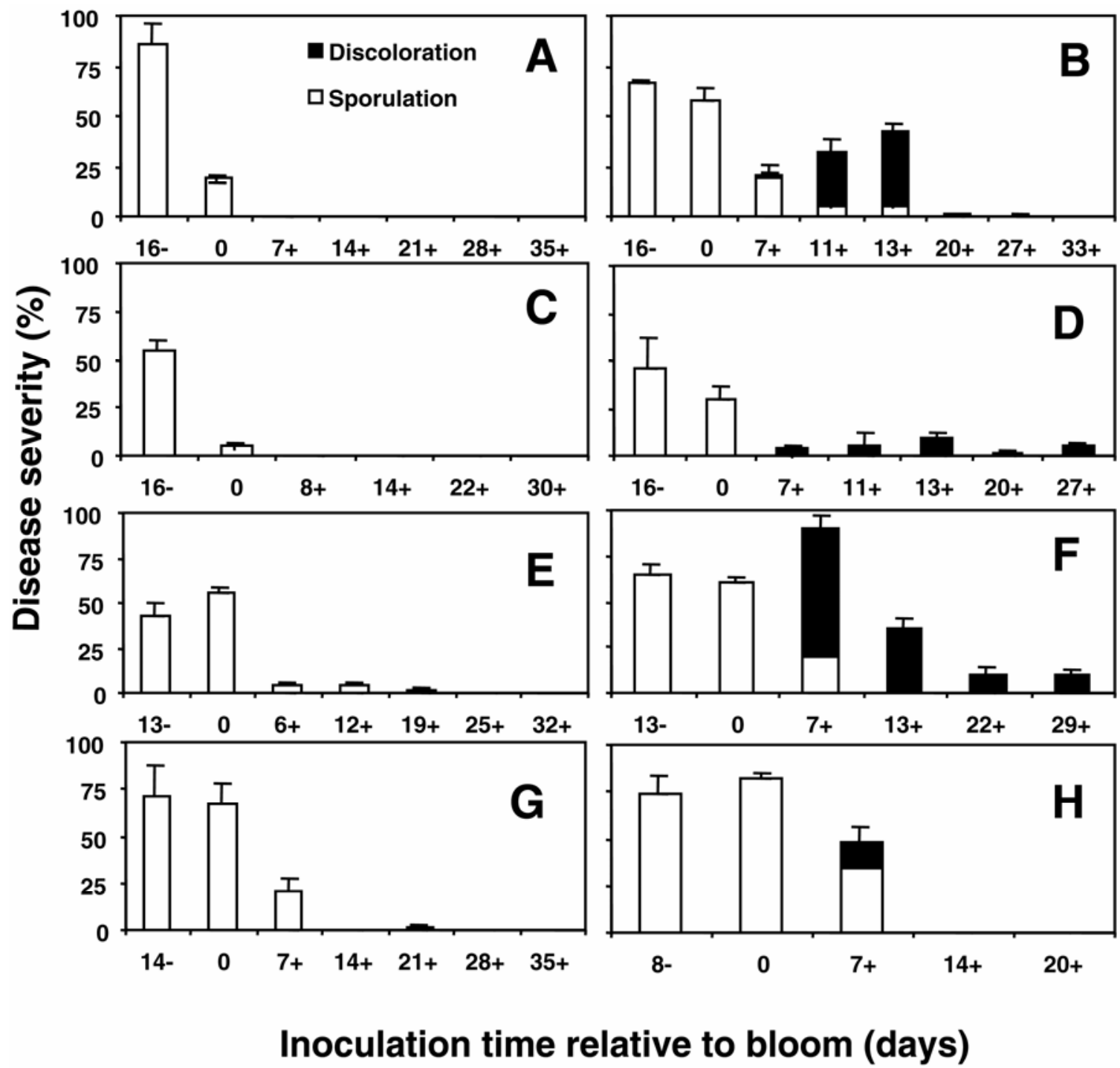

Fig. 3. Severity of downy mildew (Plasmopara viticola) on A and B, Vitis vinifera 'Chardonnay', $\mathbf{C}$ and D, V. vinifera 'Riesling', $\mathbf{E}$ and $\mathbf{F}$, V. labrusca 'Concord', and $\mathbf{G}$ and H, V. labrusca 'Niagara' clusters inoculated in Geneva, NY, in 2002 (A, C, E, and G) and 2003 (B, D, F, and H). Clusters were inoculated at the indicated times relative to the date of bloom, and severity of downy mildew (percentage of cluster surface that either supported sporulation or was discolored) was assessed 2 weeks after inoculation. Error bars refer to the mean for combined sporulation and discoloration and represent one standard error of the mean $(n=4)$.

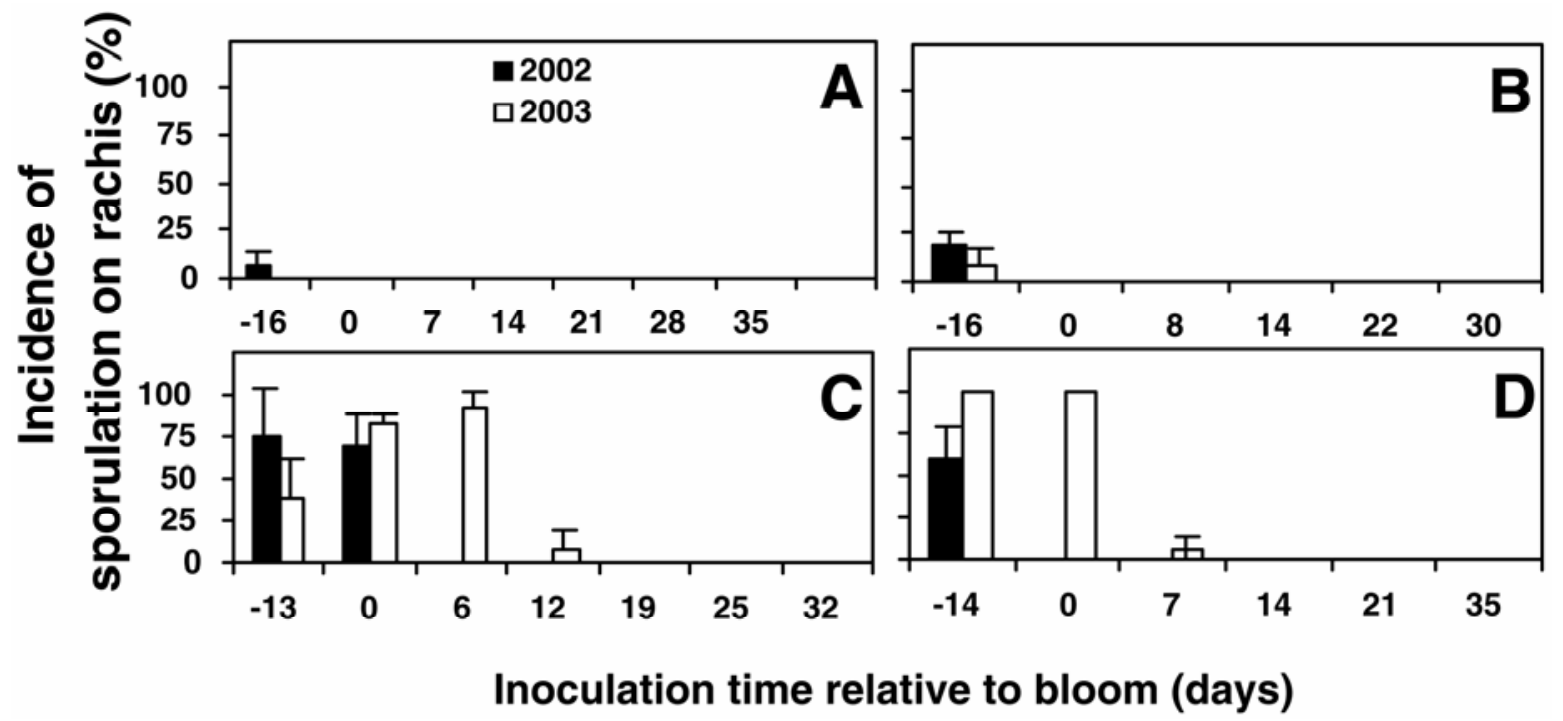

Fig. 4. Incidence of downy mildew (Plasmopara viticola) sporulation on rachises of A, Vitis vinifera 'Chardonnay', B, V. vinifera 'Riesling', C, V. labrusca 'Concord', and D, V. labrusca 'Niagara' inoculated at different stages of development in Geneva, NY, in 2002 and 2003. Clusters were inoculated at the indicated times relative to the date of bloom, and incidence of downy mildew (presence/absence of sporulation on the main rachis) was assessed 2 weeks after inoculation. Error bars represent one standard error of the mean $(n=4)$. 
On Chardonnay and Riesling vines in Geneva in 2002 and 2003, rachises rarely supported sporulation, and sporulation was generally confined to clusters inoculated at prebloom and bloom (Fig. 4A and B). The incidence of sporulation on rachises on Niagara and Concord clusters was much higher (Fig. 4C and D). In all cultivars, the rachis no longer supported sporulation when inoculated after $12 \mathrm{DAB}$.

Despite the variability among years and cultivars in Geneva, berries of all cultivars supported little sporulation and developed very little discoloration when inoculated after 200 degree-days (base $=10^{\circ} \mathrm{C}$ ) after bloom in 2002 and 2003 (Fig. 5A). After scaling and grouping of the Geneva data for each cultivar as described above, regression of relative disease severity against degree-days accumulated since bloom yielded

$$
\begin{aligned}
\text { Chardonnay } & Y=1.024-0.388 \log (X+1) \\
\text { Riesling } & Y=0.973-0.388 \log (X+1) \\
\text { Concord } & Y=1.100-0.375 \log (X+1) \\
\text { Niagara } & Y=1.025-0.410 \log (X+1)
\end{aligned}
$$

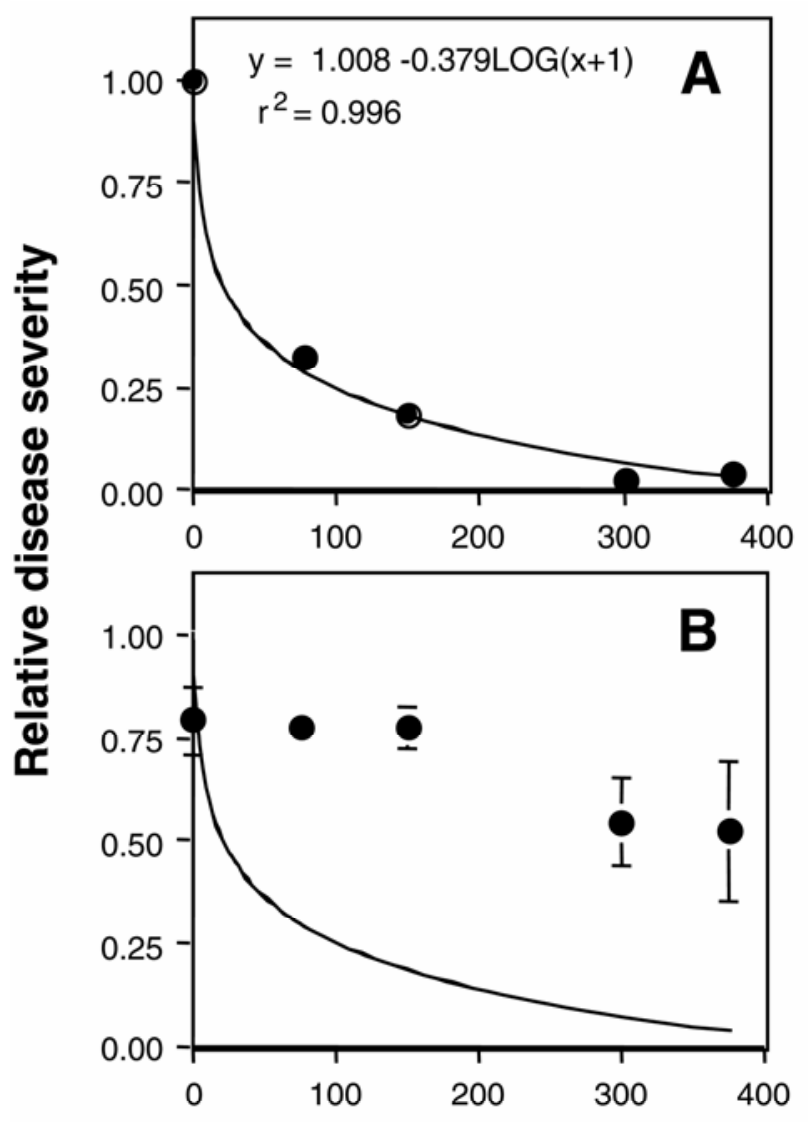

\section{Inoculation time relative to bloom (Cumulative degree-days, base $=10^{\circ} \mathrm{C}$ )}

Fig. 5. Relative severity of downy mildew on clusters of A, Vitis vinifera 'Chardonnay' and 'Riesling' and V. labrusca 'Concord' and 'Niagara' clusters inoculated at different stages of development in Geneva, NY, in 2002 and 2003 and B, 'Chardonnay' and 'Riesling' clusters inoculated in Loxton, SA, in 2001 and 2002. Relative severity was set equal to 1.0 at prebloom and bloom, and subsequent severity for each cultivar-year combination was scaled to that maximum. Data were pooled for intervals of 75 degree-days (base $10^{\circ} \mathrm{C}$ ), which approximated 1 week intervals, and regression analysis of the Geneva data generated a model for each cultivar. After confirming that regression coefficients among cultivars was not significantly different, the Geneva data were pooled to generate the equation in $\mathbf{A}$. Loxton data are plotted against the Geneva model in B. Error bars represent one standard error of the mean for the Loxton data. where $Y=$ relative severity and $X=$ degree-days accumulated since bloom. Regression coefficients were not significantly different $(P>0.721$ in all cases); thus, we pooled the data from all cultivars, and regression analysis of the pooled data yielded the equation $Y=1.008-0.379 \log (X+1)\left(r^{2}=0.996\right)$.

In Geneva, where we observed signs and symptoms weekly or bi-weekly, clusters infected at prebloom, bloom, or 1 week postbloom continued to sporulate for at least 4 to 5 weeks (Fig. 6). At 1 week postinoculation, sporulation was detected but had not fully developed, and the highest sporulation levels were observed 2 to 4 weeks after inoculation.

In Loxton, Chardonnay and Riesling clusters remained susceptible for a longer period than was observed in Geneva (Fig. 7). The period during which clusters supported extensive sporulation was 1 to 2 weeks longer than that observed in Geneva, and berries became discolored following inoculation until at least 41 DAB. Susceptibility of Riesling and Chardonnay vines at Loxton (Fig. 7) never declined to the levels observed in Geneva (Figs. 2 and 3) during the period of observation. Further, the Loxton data clearly did not fit the model developed for Geneva (Fig. 5B). At 200 degree-days, when clusters in Geneva were highly resistant (Fig. 5A), relative severity in Loxton was $>50 \%$ (Fig. 5B).

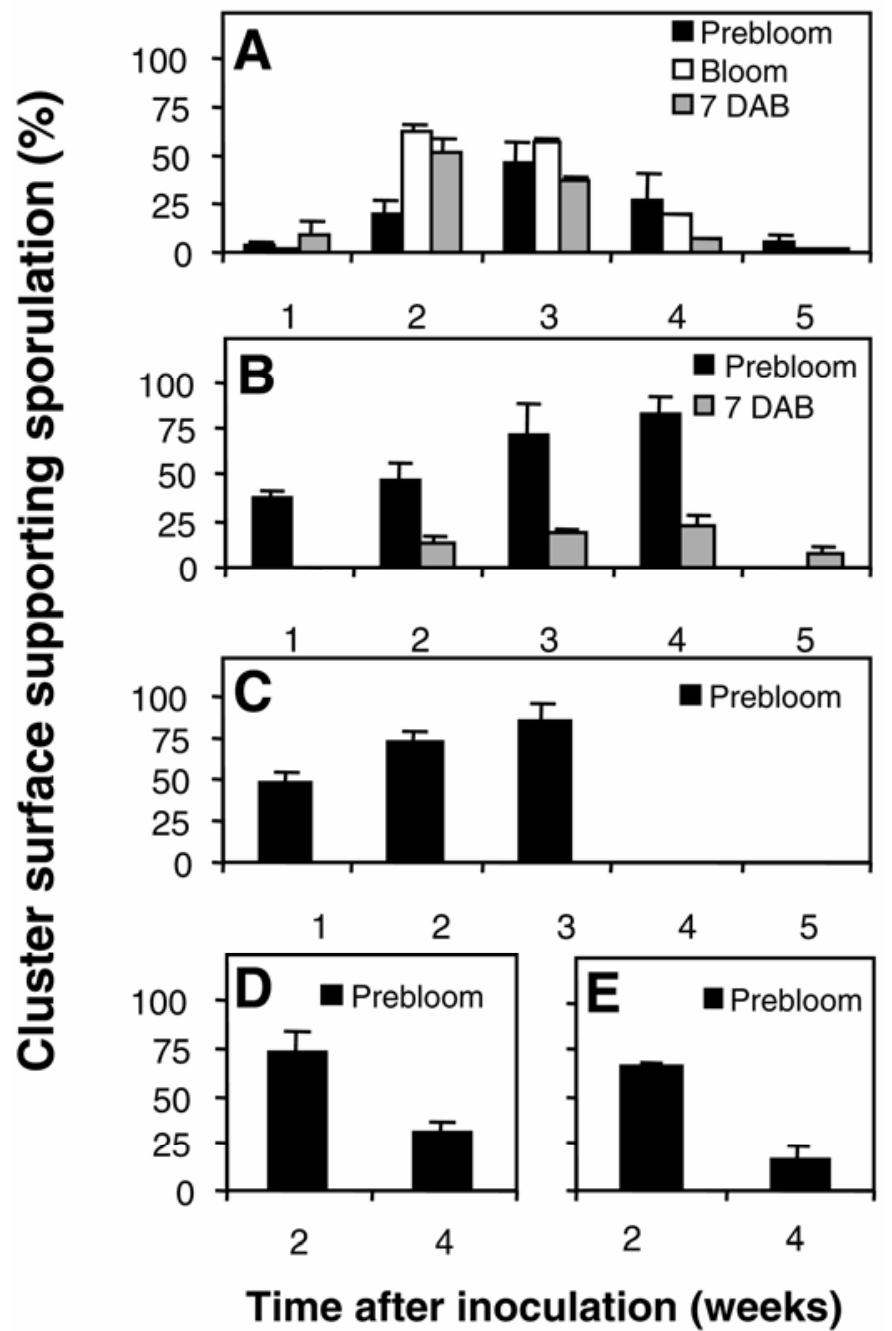

Fig. 6. Duration of sporulation of Plasmopara viticola on Vitis labrusca 'Niagara' clusters inoculated in A, 2001, B, 2002, or D, 2003 and V. vinifera 'Chardonnay' clusters inoculated in C, 2002 or E, 2003 in Geneva, NY. Clusters were inoculated at prebloom, bloom, or 7 days after bloom (DAB) as indicated, and the percentage of berries sporulating was assessed weekly (A, $\mathbf{B}$, and $\mathbf{C}$ ) or bi-weekly (D and E). Error bars display one standard error of the mean $(\mathbf{A}, n=3 ; \mathbf{B}$ to $\mathbf{D}, n=4)$. 


\section{DISCUSSION}

In previous reports, the inconsistency of the duration of grapevine fruit susceptibility to downy mildew could reflect differences in the innate susceptibility of different cultivars, differences in the tissues assessed (berries, pedicels, or rachis), or differences in the symptoms of disease (discoloration and necrosis) or signs of the pathogen (sporulation) that were recorded as responses. Interpretation of previous studies could be further confounded by an interaction of climate with the duration of bloom (11), i.e., warmer winters and minimal chilling during host dormancy is associated with protracted bloom (5). In Geneva, where flowering is relatively synchronous, most berries no longer supported sporulation if inoculated later than 1 to 2 weeks postbloom. Our results indicate the acquisition of a high level of ontogenic resistance in berries that is consistent with fungicide timing trials in New York and nearby Pennsylvania, where excellent disease control was observed if fungicidal protection was maintained until approximately 3 weeks postbloom and where additional later applications did not provide additional suppression of disease on berries (23-25).

After flowering is complete, there is a brief period when berries are highly susceptible and support high levels of sporulation. Severity of disease at the most susceptible stages was similar across cultivars, and clusters infected at prebloom, bloom, or 7 days postbloom can potentially produce high numbers of sporangia for several weeks (Fig. 6). Thereafter, there appears to be a period during which berries can be infected, become colonized, and eventually become discolored as a consequence, but will not support sporulation. Our observations of sporulation through artificial incisions demonstrate that $P$. viticola is often present in the discolored berries. Its presence within such berries could occur by two avenues. First, the pathogen could enter the berry through stomata in a transitional yet functional stage. However, subsequent to passage of the latent period, the pathogen would be unable to emerge and sporulate because the stomata had transformed to lenticels. Second, the pathogen might enter the otherwise resistant berry through the still-susceptible pedicel, proliferate internally, but again be unable to sporulate due to conversion of the stomata to lenticels. The capacity of the $P$. viticola to sporulate through wounds has not been previously reported. Independent of whether the pathogen sporulates from symptomatic berries, these berries fail to develop normally and frequently drop from the cluster. Thus, from a management perspective, early and late berry infection as well as rachis and pedicel infection all contribute to loss of yield and crop quality.

Although cultivars differed in the severity of disease that developed following inoculation, we observed only slight differences in the times when berry and pedicel tissues of the four cultivars acquired ontogenic resistance, particularly in Geneva. Ontogenic resistance to $P$. viticola generally developed later in pedicel than in berry tissue in all cultivars, similar to the differential development of ontogenic resistance to U. necator in berry and rachis tissues of Concord grapes (9), and in contrast to the simultaneous development of ontogenic resistance to $U$. necator reported for berry and rachis tissues of four $V$. vinifera cultivars (10).

The duration of berry susceptibility was much longer in Loxton than in Geneva (Fig. 5). This protracted berry susceptibility was associated with protracted bloom in Loxton compared with Geneva. For example, in 2003 the average number of days for all flowers in one cluster to bloom was 4.5 days in Geneva (standard error $=0.19$ ) versus 8.8 days (standard error $=0.416$ ) in Loxton. This difference remained when time was expressed as degreedays, i.e., 53.1 degree-days (base $=10^{\circ} \mathrm{C}$ ) accumulated during bloom in Geneva compared with 74.4 degree-days in Loxton. Thus, bloom lasted longer in Loxton in 2003 despite the accumulation of more heat units during the bloom period. Similar differences in duration of bloom and heat-unit accumulation during bloom were noted for other years of the study.

Midwinter temperatures are substantially warmer in Loxton than in Geneva, i.e., the mean midwinter (December, January, and February) temperature at Geneva is $-4.1^{\circ} \mathrm{C}$, while the comparable winter period at Loxton (June, July, and August) is $11.2^{\circ} \mathrm{C}$. While temperatures at Loxton were sufficiently low to satisfy the chilling requirement of grapevines, additional chilling promotes synchronous flowering (5), albeit to a presently unknown or poorly understood degree. For reasons that also remain unclear, the difference in duration of bloom between the two locations ( 4.3 days) was less than the difference in duration of berry susceptibility (Fig. 5). We are in the preliminary stages of an extensive study of how climate affects phenological heterogeneity in grapevine (11). This study may reveal how winter climate can extend flowering periods and thereby affect subsequent development of ontogenic resistance and severity of disease. In conjunction with the above, a precise description of the development of ontogenic resistance under conditions of synchronous flowering may eventually allow us to adjust a model of ontogenic resistance for climate-related asynchronous flowering.

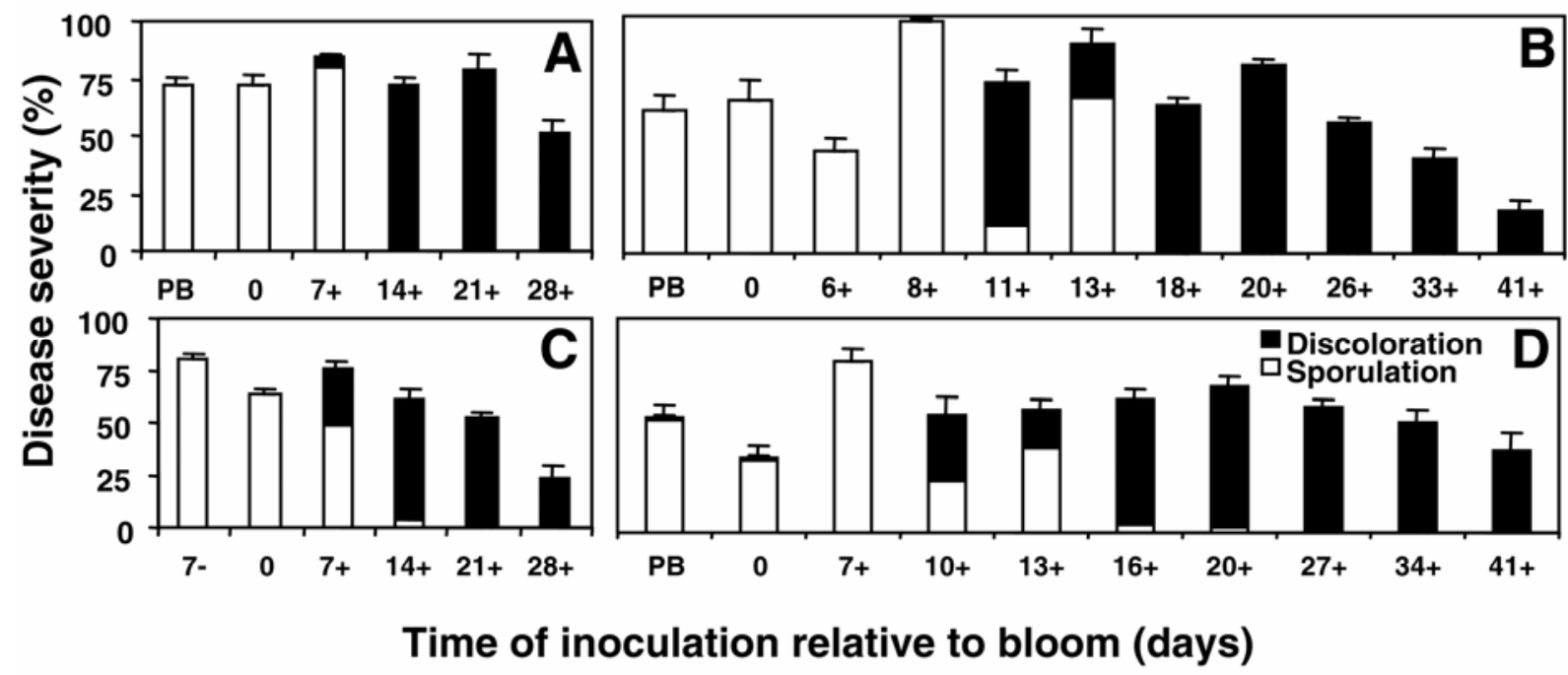

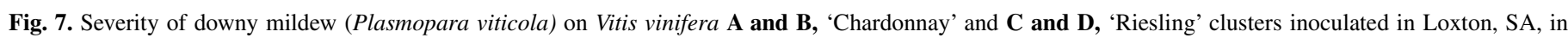

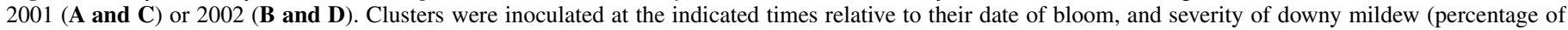

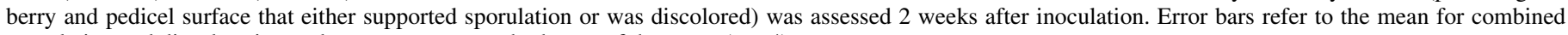
sporulation and discoloration and represent one standard error of the mean $(n=4)$. 
DMCast (21) accurately estimates the date of bloom (50\% capfall) for the Finger Lakes region of New York, based upon observed local weather. Integrating DMCast's phenology and infection models with the equation shown in Figure 5A allows us to consider the development of ontogenic resistance in fruit clusters in management of downy mildew. For example, DMCast identified 37, 21, and 56 infection events during the 2001, 2002, and 2003 growing seasons for Geneva, respectively. However, only 13,5 , and 9 of these infection events respectively, occurred during the period when fruit were predicted to be susceptible. Although maintenance of a healthy and functional canopy is essential to production of high-quality fruit, the presence of healthy foliage is of little commercial value if the fruit are diseased. The value of identifying a critical period of fruit susceptibility does not diminish the importance of controlling foliar disease, but identifies precisely when protection of the salable crop is essential. In practice, relatively few fungicide applications may ultimately decide the outcome of a management program with respect to controlling downy mildew on fruit.

In addition to $P$. viticola, windows of susceptibility to infection have been described recently for $U$. necator $(9,10), G$. bidwellii $(13,14)$, and Botrytis cinerea $(27,28)$. Such information is not only critical to the efficient management of disease in a multiple pest system such as grapevine (8), but provides examples of how ontogenic resistance could be more completely utilized in other pathosystems (7), and may provide insights valuable to more fundamental studies of the mechanisms involved in ontogenic resistance.

\section{ACKNOWLEDGMENTS}

This research was partially funded by the Viticulture Consortium-East through a grant to Cornell University, NYSAES, under Agreement 343607382 and the New York State Wine and Grape Foundation, and from the Riverland Winegrape Industry Council in South Australia.

\section{LITERATURE CITED}

1. Bernard, A. 1977. Observations histologiques sur les baies de Vitis vinifera au cours de leur croissance. France Viticole 9:137-146, 172-182, 199-205.

2. Bessis, R. 1972. Etude de l'évolution des stomates et des tissus peristomatiques du fruit de la vigne. C.R. Acad. Sc. Paris 274:2158-2161.

3. Blaeser, M., and Weltzein, H. 1977. Untersuchungen über die Infektion von Weinreben mit Plasmopara viticola in Abhängigkeit von der Blattnässedauer. Meded. Fac. Landbouww. Rijksuniv. Gent 42:967-976.

4. Blaeser, M., and Weltzein, H. 1978. Die Bedeutung von Sporangienbildung, -ausbreitung und-keimung für die Epidemiebildung von Plasmopara viticola. Z. Pflanzenkr. Pflanzenschutz 85:155-161.

5. Childers, N. F., Morris, J. R., and Sibbett, G. S. 1995. Modern Fruit Science: Orchard and Small Fruit Culture. 10th ed. Horticultural Publications, Gainesville, FL.

6. Emmett, R. W., Wicks, T. J., and Magarey, P. A. 1992. Downy mildew of grapes. Pages 90-128 in: Plant Diseases of International Importance: Diseases of Fruit Crops. A. Mukhopadhyay, ed. Prentice Hall, Englewood Cliffs, NJ.

7. Ficke, A., Gadoury, D. M., and Seem, R. C. 2002. Ontogenic resistance and plant disease management: A case study of grape powdery mildew. Phytopathology 92:671-675.
8. Gadoury, D. M., Pearson, R. C., Seem, R. C., and Park, E. W. 1997. Integrating the control programs for fungal diseases of grapevine in the northeastern United States. Viticulture Enol. Sci. 52:140-147.

9. Gadoury, D. M., Seem, R. C., Ficke, A., and Wilcox, W. F. 2001. The epidemiology of powdery mildew on Concord grapes. Phytopathology 91:948-955.

10. Gadoury, D. M., Seem, R. C., Ficke, A., and Wilcox, W. F. 2003. Ontogenic resistance to powdery mildew in grape berries. Phytopathology 93:547-555.

11. Gadoury, D. M., Seem, R. C., Kennelly, M. M., and Wilcox, W. F. 2003. Climate-based temporal heterogeneity in flowering and the distribution of ontogenic resistance to major fruit diseases of grapevine. (Abstr.) Phytopathology 93(suppl.):S28.

12. Gregory, C. T. 1915. Studies on Plasmopara viticola (downy mildew of grapes). Pages 126-150 in: Proc. 1st Int. Cong. Vitic., International Congress of Viticulture.

13. Hoffman, L. E., and Wilcox, W. F. 2002. Utilizing epidemiological investigations to optimize management of grape black rot. Phytopathology 92:676-680.

14. Hoffman, L. E., Wilcox, W. F., Gadoury, D. M., and Seem, R. C. 2002. Influence of grape berry age on susceptibility to Guignardia bidwellii and its incubation period length. Phytopathology 92:1068-1076.

15. Lafon, R., and Bulit, J. 1981. Downy mildew of the vine. Pages 601-614 in: The Downy Mildews. D. Spencer, ed. Academic Press, New York.

16. Lafon, R., and Clerjeau, M. 1988. Downy mildew. Pages 11-13 in: Compendium of Grape Diseases. A. C. Goheen, ed. The American Phytopathological Society, St. Paul, MN.

17. Lalancette, N., Madden, L. V., and Ellis, M. A. 1988. Development of an infection efficiency model for Plasmopara viticola on American grape based on temperature and duration of leaf wetness. Phytopathology 78:794-800.

18. Lalancette, N., Madden, L. V., and Ellis, M. A. 1988. A quantitative model for describing the sporulation of Plasmopara viticola on grape leaves. Phytopathology 78:1316-1321.

19. Muller, K., and Sleumer, S. 1934. Biologische Untersuchungen über die Peronosporakrankheit des Weinstockes, mit besonderer Berücksichtigung ihrer Bekämpfung nach der Inkubationskalendermethode. Landwirt. Jahrbücher 79:509-576.

20. Nakagawa, S., Komatsu, H., and Yudi, E. 1980. A study of micromorphology of grape berry surface during their development with special reference to stoma. J. Jpn. Soc. Hortic. Sci. 49:1-7.

21. Park, E. W., Seem, R. C., Gadoury, D. M., and Pearson, R. C. 1997. DMCast: A prediction model for grape downy mildew development. Viticulture Enol. Sci. 52:182-189.

22. Swift, J. G., Buttrose, M. S., and Possingham, J. V. 1973. Stomata and starch in grape berries. Vitis 12:38-45.

23. Travis, J. W., and Hed, B. 2002. Evaluation of fungicides for control of downy mildew, powdery mildew, and Phomopsis cane and leaf spot of grapes, 2001. Fungicide and Nematicide Tests (online) Report 57:SMF17. The American Phytopathological Society, St. Paul, MN.

24. Wilcox, W. F., and Riegel, D. G. 2000. Evaluation of fungicide programs for control of downy mildew of grapes, 1999. Fungicide and Nematicide Tests (online) Report 55:117. The American Phytopathological Society, St. Paul, MN.

25. Wilcox, W. F., and Riegel, D. G. 2002. Evaluation of fungicide programs for control of downy mildew of grapes, 2001. Fungicide and Nematicide Tests (online) Report 57:SMF19. The American Phytopathological Society, St. Paul, MN.

26. Zachos, D. G. 1959. Recherches sur la biologie et l'épidémiologie du mildiou de la vigne en Grece. Ann. Inst. Phytopathol. Benaki 2:193-335.

27. Zitter, S. M., and Wilcox, W. F. 2001. The role of early latent infections and cluster architecture on development of Botrytis bunch rot. (Abstr.) Phytopathology 91(suppl.):S100.

28. Zitter, S. M., and Wilcox, W. F. 2002. Early Botrytis infections as sources of secondary inoculum for ripening grape berries. (Abstr.) Phytopathology 92(suppl.):S91. 